Service, Self-Care, and Sacrifice: A Qualitative Exploration of the Pandemic University as a Greedy Institution

Molly Dingel, Marcia Nichols, Angie Mejia, and Kristin Osiecki

University of Minnesota Rochester 


\begin{abstract}
Scholars have argued that higher education is a "greedy institution" that monopolizes employees" time and energy. Further, women and minoritized faculty bear the heaviest burdens of these demands with respect to teaching and service. In this autoethnographic paper, we explore the escalating demands of the greedy institution during the COVID-19 pandemic.
\end{abstract}

Keywords: greedy institution, COVID, autoethnography 


\section{Service, Self-Care, and Sacrifice: A Qualitative Exploration of the Pandemic University as a Greedy Institution}

Wright et al (2004) identifies higher education as a "greedy institution" that places high demands on employees' loyalty and seeks to reduce the competing roles of those employees. These demands are not placed equally on all faculty members: women spend less time on research and more time on teaching and service, specifically on lower-prestige service activities (Guarino \& Borden, 2017). Women and minoritized faculty also experience additional demands on their time compared to their white male counterparts (Hirshfield \& Joseph, 2012). This paper uses autoethnographic methods to explore institutional and faculty responses to the COVID-19 pandemic and police brutality of George Floyd 80 miles from our campus. Our integration of our vulnerable selves is an intentional methodological as well as intellectual move. As Jones, Adams, and Ellis (2016) argue, autoethnographic writing is a relational act that uses vulnerability to compel a response from the reader. As four women faculty, three white and one Latina, at different stages in our careers, we believe that candidly sharing our experiences trying to satisfy a greedy institution will resonate with others faced with similar demands.

\section{Teaching: Molly, Associate Professor}

Prior to COVID, I had never taught (or taken) an online course, had no sense of how to teach online, what strategies "good" online courses used, or how to engage students in a rich learning experience online. Revising my courses meant a steep learning curve and using my summer research and rejuvenation time. I took an online course that covered some best practices in online teaching. To prepare, I spent hours recording lectures, revising content, and brainstorming about how to keep the course interactive, and students engaged. 
This shift to online reveals the greedy institution at work. Messaging from our administration in spring "20 indicated that they wanted us to "prioritize" in-person instruction, while also creating a parallel online course (and creating "the best possible learning experience") to meet students' safety needs. There was no parallel statement about meeting faculty's safety needs or acknowledging the effort of offering a course parallel online and in-person. Throughout the semester, the administration bombarded us with other teaching requests: the creation of a blended or fully online offering of our program, collaboration with area high schools, and asking faculty to break down the boundary between work and personal life by sending students personal text messages, sharing our stress with them, and "modeling self-care strategies" for them. At a time when I am spending more time than normal on teaching, the institution wants even more, making me constantly evaluate whether I am doing enough.

\section{Service: Marcia, Associate Professor}

In addition to serving on the departmental steering committee, I served as one of the faculty senators on the system Faculty Senate, and as the campus liaison to the system's Faculty Consultative Committee (FCC). Since March of 2020, these committees required extra work and mental energy. The FCC went from monthly to weekly meetings throughout the Spring and most of Summer 2020, in order to navigate the new pandemic ambiguities and budget crises. The Senate required numerous (uncompensated) special sessions when it is normally in recess to discuss and vote on the budgetary crisis, including asking all of us to vote to reduce our own pay even though we were doing extra work. In addition, the civil unrest caused by the murder of George Floyd brought calls to reform and demilitarize campus police on the Twin Cities campuses. The FCC and Senate were also tasked with reviewing and revising our Sexual Assault and Harassment procedures to bring them into line with the new Title IX requirements by the 
Department of Education. Moreover, these system committees regularly met with the president, the provost, and other leaders, so I knew information about which our own administration was not forthcoming. This enabled me to challenge our local administration, especially about teaching modalities. Even with tenure, challenging the greedy institution is fraught with anxiety.

\section{Mentoring: Angie, Assistant Professor}

"It appears your workload is low for the term..." His friendly email and a series of communications and meetings with other administrators suggested a way to "fix" this problem: develop a new class on intersectionality and health. Since my research interests aligned with the Chancellor's mandate of integrating anti-racism into the curriculum, preparing this class would be a "mutually beneficial opportunity." If it weren't for two tenured women faculty who noticed that others with low workloads were not being asked to do a new prep in two weeks or less, I would have had to cut my sleep in half to prepare, since weekends are already non-existent. So much for practicing self-care as the Chancellor also continually urged. Each Saturday and Sunday, I find myself supporting racially minoritized students who navigate not only two societal crises, but also an institutional context that boasts more than one-third of the student body as "racially diverse" yet is woefully unprepared to meet their specific needs. One way greedy institutions extract labor from someone like me is by "gently" enforcing administrative guidelines while ignoring the amount of time that BIPOC faculty dedicate to listening to and supporting students of color. Since March 2020, many of these students have asked me to listen and hear, sometimes for the first time, recollections of being othered, daily, by peers, instructors, employers, the guy who rides the bus, and so many other "nice" (white) Minnesotans. This is a form of labor that I cannot turn my back on and cannot discharge onto someone else. My first year as the only Woman of Color in the tenure-track had me connecting with students of color in 
unexpected ways. For instance, emails by students seeking support take the peculiarities of a Dear Abby submission ... if Dear Abby was dispensing advice on how one should navigate the racialized day-to-day microviolences of the Midwest. "Dear Professor... My family's front neighbor ... [L]ast week... put up the American flag. This week he put up this. [I get a picture of a White supremacist symbol.] I'm a bit curious if he is a white supremacist..." After setting up a meeting over Zoom, I am also curious... Which annual review category should "determining racial hate symbols while comforting students over Zoom" be listed under? And will the time spent reassuring students of our humanity as Black and Brown women in STEM worlds be enough to satisfy having a low teaching load this term?

\section{Research: Kristin, Assistant Professor}

Emergency pandemic emails flood my inbox with vague remote working guidelines, creating an online curriculum, and urgent Zoom sessions on "getting back to normal." But all that virtual noise offers no guidance for navigating my cancelled research sabbatical leave, scrapped inperson data collection, and inhumane service and teaching loads. Platitudes about focusing on future publishing opportunities fail to comfort me as I mourn the abrupt end to my research with countless hours of planning and collecting in-class data collection tragically gone. Calls to remember to take care of myself seem cruel and mocking. This is exacerbated when the greedy institution fails to provide basic grant support. That failure turns into exponentially more invisible time and effort from me that I cannot continue to give and eats away at the time of my female colleagues when I turn to them for the support and advocacy I need. Administration supports those staff and faculty who worked so hard for a safe return of students to campus, to provide instruction for multiple modalities, to create new endeavors to support student belonging, and to support hours of summer preparation. Yet, they continue ghosting research. 
Studies show that lockdown and social distancing penalize women academics with statistically significant negative effects on women in the fields of health and medicine, and social sciences (Squazzoni et al., 2020). Reassurance of the extended tenure clock with a guaranteed renewal of my appointment is overwhelmingly stressful. Extensions decrease long-term earning potential, and women are unconsciously penalized for productivity loss in comparison to men (Malisch et al., 2020). Writing an impact statement for my current annual review to justify my performance during never-ending crises, forces me to relive the loss of my learning research, my disproportionate service load, and the inordinate time re-designing online curriculum with complete exhaustion. The greedy institution's cold comforts only ask more of me.

\section{Summary}

Our experiences are not unique; declining public funding combined with a wide range of services demanded by students or required by law have pushed universities to adopt austerity measures that require more of faculty and staff while advertising a student-based customer service model. The pandemic and social unrest has accelerated these demands of the greedy institution, which permeate all the major areas of academic life: research, teaching, mentoring, and service. Although the pandemic did not create this insatiableness, it has laid it bare. Even though we are each at a different career stage and have differing amounts of institutional power, we have each been faced with the demands of a greedy institution that is never satisfied, that always demands more, even when we have nothing left to give.

Faculty burnout is becoming a pandemic in itself, and it cannot be cured through individual self- care. Burnout must be addressed as an institutional problem (Moss, 2021) collaboratively and proactively by faculty and higher ed administration. Further, this collaboration must also address that workload is not equitably distributed; those with less social 
power (women, BIPOC, and untenured faculty) exist in less stable academic positions while facing increased requests for time and emotional and mental energy.

Research identifies four factors that are related to perceptions of and satisfaction with workload that institutions should adopt: transparency that details the work activities of those in the department; objective evaluation criteria to prevent bias in evaluations; rotation of timeintensive, less-promotable but necessary work; and reward systems that recognize the context of individuals' workloads and a transparent process to modify workloads (O'Meara et al., 2018, 2019). We hope that the light shed on these problems in special issues like this one will stimulate the necessary changes to make institutions like ours less greedy and more invested in mutual care. 


\section{References}

Guarino, C. M., \& Borden, V. M. H. (2017). Faculty Service Loads and Gender: Are Women Taking Care of the Academic Family? Research in Higher Education, 58, 672-694.

Hirshfield, L. E., \& Joseph, T. D. (2012). ‘We need a woman, we need a black woman’: Gender, race, and identity taxation in the academy. Gender and Education, 24(2), 213-227.

Jones, S. H., Adams, T. E., \& Ellis, C. (Eds.). (2016). Handbook of Autoethnography. Routledge. Malisch, J. L., Harris, B. N., Sherrer, S. M., Lewis, K. A., Shepherd, S. L., McCarthy, P. C., Spott, J. L., Karam, E. P., Moustaid-Moussa, N., Calarco, J. M., Ramalingam, L., Talley, A. E., Cañas-Carrell, J. E., Ardon-Dryer, K., Weiser, D. A., Bernal, X. E., \& Deitloff, J. (2020). In the wake of COVID-19, academia needs new solutions to ensure gender equity. Proceedings of the National Academy of Sciences, 117(27). https://doi.org/10.1073/pnas.2010636117

Moss, J. (2021, February 10). Beyond Burned Out. Harvard Business Review. https://hbr.org/2021/02/beyond-burned-out?fbclid=IwAR0FZ24TjjzuHfxkg76UW8Tc_CA9WtkRW3BDrw4sknCGQttHxzGg2mjKVQ

O’Meara, K., Jaeger, A., Misra, J., Lennartz, C., \& Kuvaeva, A. (2018). Undoing disparities in faculty workloads: A randomized trial experiment. PLoS ONE, 13(12), e0207316.

O’Meara, K., Lennartz, C. J., Kuvaeva, A., Jaeger, A., \& Misra, J. (2019). Department Conditions and Practices Associated with Faculty Workload Satisfaction and Perceptions of Equity. The Journal of Higher Education, 90(5), 744-772.

Squazzoni, F., Bravo, G., Grimaldo, F., Garcia-Costa, D., Farjam, M., \& Mehmani, B. (2020). No Tickets for Women in the COVID-19 Race? A Study on Manuscript Submissions and 
Reviews in 2347 Elsevier Journals during the Pandemic. SSRN. https://papers.ssrn.com/sol3/papers.cfm?abstract_id=3712813

Wright, M. C., Howery, C. B., Assar, N., McKinney, K., Kain, E. L., Glass, B., Kramer, L., \& Atkinson, M. (2004). Greedy Institutions: The Importance of Institutional Context for Teaching in Higher Education. Teaching Sociology, 32(2), 144-159. 